\title{
Espaços promotores de saúde na Atenção Básica: a experiência dos graduandos de Odontologia da Universidade Estadual da Paraíba
}

\author{
Lilian Nadja Silva Brito*; Renally Cristine Cardoso Lucas**; Fernanda Ferreira Andrade*; Ygor \\ Alexandre Beserra*; Rilva Suely de Castro Cardoso Lucas***; Renata Rocha Cardoso Madruga***; \\ Gabriella Barreto Soares**** \\ * Graduanda em Odontologia, Universidade Estadual da \\ Paraíba, Campina Grande \\ ** Cirurgiã-dentista preceptora da Unidade de Saúde da \\ Família Argemiro Figueiredo, Campina Grande \\ *** Professora Doutora, Departamento de Odontologia, \\ Universidade Estadual da Paraíba, Campina Grande \\ **** Professora Doutora, Departamento de Promoção de Saúde, \\ Centro de Ciências Médicas da Universidade Federal da \\ Paraíba, João Pessoa
}

Recebido: 26/05/2020. Aprovado: 18/11/2020.

\begin{abstract}
RESUMO
O estudo tem por objetivo relatar a experiência de um grupo de acadêmicos de Odontologia da Universidade Estadual da Paraíba, ocorrida no segundo semestre de 2018, durante o processo de formação de um espaço promotor de saúde que proporcionou o encontro da cultura e arte com o Sistema Único de Saúde na Unidade de Saúde da Família (USF) Argemiro de Figueiredo, situada no município de Campina Grande. A construção deste espaço ocorreu durante o Estágio na Estratégia Saúde da Família I, componente curricular ofertado no quarto semestre do curso. Tal ambiente foi criado a partir da realização da vivência intitulada de "Grafite que traz vida", como também por meio do processo de construção da Horta Comunitária na USF em questão. As atividades citadas foram marcadas pela forte interação entre acadêmicos, comunidade, equipe de saúde e equipamentos sociais presentes na área adstrita à USF, permitindo, assim, o fortalecimento do vínculo entre equipe de saúde e população. Neste processo de vivência em comunidade, observou-se a importância da presença de acadêmicos de Odontologia no cenário da Atenção Básica (AB). Tal presença possibilitou que os mesmos reconhecessem a relevância do cuidado integral, entendendo, assim, que o papel do cirurgião-dentista na $\mathrm{AB}$ vai muito além da garantia de assistência em saúde bucal para a população. Além disso, a construção de um espaço promotor de saúde permitiu o fortalecimento dos laços entre os usuários e trabalhadores fazendo com que a comunidade compreendesse o espaço da UBS para além da doença.
\end{abstract}

Descritores: Estratégia Saúde da Família. Apoio ao Desenvolvimento de Recursos Humanos. Odontologia. Promoção da Saúde. 


\section{INTRODUÇÃO}

De acordo com a definição do Ministério da Saúde, a Atenção Básica (AB) se constitui como a principal porta de entrada do Sistema Único de Saúde (SUS) e pode ser considerada como ponto de partida para a estruturação dos sistemas locais de saúde ${ }^{1}$. A AB permite que os usuários tenham o seu primeiro contato com o SUS, devendo estabelecer o cuidado integral à saúde, com atividades de promoção e prevenção, trabalhos de detecção precoce e o rastreamento de doenças, bem como o tratamento e a reabilitação ${ }^{2}$. Também é de atribuição da $\mathrm{AB}$ realizar orientação familiar e comunitária e de competência cultural ${ }^{3}$.

$O$ fortalecimento da $\mathrm{AB}$ a partir da reorganização do SUS e a consolidação da Estratégia Saúde da Família (ESF) tem auxiliado na redução das desigualdades e irregularidades no que diz respeito ao acesso aos serviços de saúde 4 . É importante destacar que a nova Política Nacional de Atenção Básica (PNAB), aprovada em setembro de 2017 pela portaria ${ }^{\circ} 2.436$, sustentou que a ESF é a estratégia de maior prioridade para a expansão e consolidação da $\mathrm{AB}$, e, além disso, reforçou o papel da $\mathrm{AB}$ por meio da articulação com importantes iniciativas do SUS, como a ampliação das políticas intersetoriais e de promoção de saúde .

Nesse contexto, é válido salientar a importância da atuação territorializada do profissional da saúde atuante na ESF, uma vez que é perceptível que este tipo de atuação favorece a criação de um vínculo com a população, por meio do fortalecimento das ações intersetoriais ${ }^{6}$. Sendo assim, é possível afirmar que tal vínculo permite o estabelecimento da longitudinalidade do cuidado e favorece a promoção da saúde e a prevenção de agravos, permitindo o diagnóstico precoce de algumas doenças. Por esses motivos, o conhecimento da comunidade na qual o usuário vive é crucial para o desempenho das atividades dos profissionais da saúde, não apenas do âmbito exclusivo da doença, mas também no âmbito físico, social e cultural.

Sendo assim, a importância da criação desses vínculos entre os profissionais e usuários que transcendem os trabalhos focados na doença deve ser transmitida para os futuros profissionais da área da saúde durante a sua formação, objetivando o perfil de profissionais sensíveis, humanizados e que, de fato, compreendam a relevância de se construir vínculos com a comunidade e sua importância no desempenho das atividades na unidade de saúde.

Nesse sentido, o SUS é ordenador da formação dos recursos humanos em saúde, como descrito na Constituição Federal, que aponta a necessidade da reorientação da formação nos cursos da saúde ${ }^{7}$. Assim, várias ações foram adotadas para buscar a concretização de inovações educacionais nos cursos de graduação de modo que os princípios do SUS fossem alcançados. Entre essas ações, as mudanças nas Diretrizes Curriculares Nacionais (DCN) para as profissões da área de saúde, que preconizam a ruptura do modelo de currículo mínimo obrigatório para as carreiras, como possibilidade para a perspectiva transformadora da formação de trabalhadores da saúde ${ }^{8}$.

Desse modo, quando o enfoque principal é o curso de Odontologia, é de grande valia ressaltar a criação do Programa Nacional de Reorientação da Formação em Saúde (Pró-saúde), que permitiu a aproximação entre os mundos acadêmico e o de prestação real de serviços de saúde ${ }^{9}$; como também destacar a elaboração das DCN dos cursos de graduação em Odontologia. Estas diretrizes definiram que a formação do cirurgião-dentista deve dotar o profissional de conhecimentos necessários para o exercício de competências e habilidades que visem às ações de promoção, prevenção, proteção e reabilitação de saúde nos níveis individual e coletivo ${ }^{10}$. Da mesma forma, deverá contemplar o sistema de saúde vigente no 
país, a atenção integral da saúde num sistema regionalizado e hierarquizado de referência e contrarreferência e o trabalho em equipe. As mesmas diretrizes também recomendam que os conteúdos essenciais para o curso de graduação em Odontologia devem estar relacionados com todo o processo saúde-doença do cidadão, da família e da comunidade, integrado à realidade epidemiológica e profissional.

Desta forma, percebeu-se a necessidade da reformulação curricular, permitindo que, a partir de atividades extramuros, os graduandos passassem a ter seus primeiros contatos com a necessidades da população nos serviços da Atenção Básica.

Assim sendo, considerando as discussões apresentadas anteriormente e a importância da interação entre a universidade, a comunidade e os serviços de saúde, o curso de Odontologia da Universidade Estadual da Paraíba (UEPB) Campus I oferece aos acadêmicos o componente curricular " Estágio na Estratégia Saúde da Família”. Os alunos realizam o estágio semanalmente na USF pré-determinada acompanhados de um professor tutor e de um preceptor que ocupa cargo de cirurgião-dentista na referida unidade.

Diante desse contexto, o presente artigo tem como objetivo relatar a experiência da interação entre um grupo de acadêmicos do quarto semestre do curso de Odontologia, comunidade e equipe de saúde da USF Argemiro de Figueiredo, pertencente ao Distrito Sanitário V do município de Campina Grande - Paraíba. As vivências a serem relatadas são as da oficina "Grafite que traz vida" e da construção de uma horta comunitária na USF, destacando a importância dessas atividades na criação do vínculo entre os usuários, equipe de saúde e acadêmicos.

\section{RELATO DE EXPERIÊNCIA}

Trata-se de um relato de experiência elaborado a partir dos registros e anotações realizados durante a condução da primeira edição da disciplina "Estágio na Estratégia Saúde da Família I". A experiência apresentada é resultado da parceria do curso de Odontologia da UEPB Campus I, com a Secretaria Municipal de Saúde (SMS) de Campina Grande, que juntas proporcionam aos estudantes o Estágio na Estratégia Saúde da Família. Tal componente faz parte do projeto pedagógico do curso, e permite que no quarto e no sexto semestres da graduação os estudantes realizem atividades que tenham como enfoque principal a prevenção e a promoção da saúde com aplicação dos conhecimentos nos mais variados ambientes do território da área de abrangência de uma USF.

O município de Campina Grande, situado no agreste paraibano, abriga uma população de 409.731 habitantes em uma área de 591,658 km² $\left(648,31 \mathrm{hab} / \mathrm{km}^{2}\right)$, seu Índice de Desenvolvimento Humano (IDH), no ano de 2010, foi de $0,720^{11}$ e seu Índice de Gini foi de $0,5859^{12}$. Este município exerce grande influência política e econômica no recorte geográfico do "Compartimento da Borborema", representado por mais de 60 municípios, com uma população de cerca de 1 milhão de habitantes ${ }^{11}$.

A Rede de Atenção à Saúde (RAS) do sistema municipal da cidade de Campina Grande é composta de uma rede poliárquica de serviços que tem como porta de entrada a $\mathrm{AB}$, formada por 137 USF, entre outros equipamentos ${ }^{13}$.

A UEPB, com sede localizada no município acima descrito, é uma autarquia estadual com oito campi. O curso de Odontologia é atualmente ofertado nos campi I (Campina Grande) e VIII (Araruna) e, em ambos, sua duração é de cinco anos. É válido ressaltar que o curso de Odontologia do Campus I foi um dos primeiros cursos implantados na UEPB e o primeiro da área da saúde, há quase 50 anos. O projeto pedagógico do curso (PPC) foi reformulado no ano de 2016, de acordo com as DCN e, nesta nova versão, é 
perceptível que se buscou maior enfoque na área da Saúde Coletiva durante o processo de formação dos futuros cirurgiões-dentistas.

Sendo assim, cabe destacar que o novo PPC permitiu que houvesse a readequação e o fortalecimento da articulação entre práticas de ensino, serviços e necessidades da comunidade por meio da intersecção da instituição de ensino com a SMS do município; sendo esta integração ensinoserviço-comunidade uma demanda das DCN que prevê novos cenários de práticas para os graduandos da área da saúde.

Para que a disciplina de estágio aconteça, semestralmente é realizado um encontro com a Coordenação de Saúde Bucal da SMS, que por sua vez determina as USF que estão disponíveis para a realização do estágio. Todos os discentes preenchem um Termo de Compromisso, no qual estão descritas as ações a serem desenvolvidas no estágio, devidamente acordadas e assinadas pelos professores supervisores, preceptores do serviço, Coordenadora de Saúde Bucal e o setor competente da Pró Reitoria de Graduação (PROGRAD) da UEPB, que providencia o seguro coletivo dos alunos que irão participar do estágio.

É válido destacar que antecedem o estágio duas disciplinas: "Introdução à Epidemiologia" e "Políticas de Saúde", ofertadas, respectivamente, no segundo e no terceiro semestres do curso; ambas consideradas pré-requisitos do componente curricular "Estágio na Estratégia Saúde da Família I'. Sendo assim, antes da vivência do estágio, os graduandos estudam desde os primeiros conceitos e noções de epidemiologia, até o surgimento e consolidação do SUS, bem como o funcionamento das estratégias que permitem o exercício dos seus princípios e diretrizes em todos os níveis de atenção à saúde, em especial, na $\mathrm{AB}$.

A disciplina "Estágio na Estratégia Saúde da Família I", que no novo PPC faz parte do grupo de disciplinas básicas específicas de estágio, tem o objetivo de desenvolver atividades com enfoque educativo, preventivo e de promoção à saúde com aplicação dos conhecimentos em ambientes do território da área de abrangência de uma USF, promovendo, assim, a integração do aluno com a comunidade e serviço de saúde.

Nesta experiência, o estudante estabelece uma conexão interprofissional e desenvolve competências potentes para a sua formação, além do agir colaborativo. Ao desenvolver a competência da atenção à saúde, onde pode apontar soluções para problemas que porventura ocorram no ambiente do estágio, é possível junto com o preceptor e professor supervisor, desenvolver habilidades para avaliar, sistematizar e tomar decisões quanto às melhores escolhas, baseadas na ciência, outra importante competência considerada na formação. O processo de comunicação, é um aspecto bastante positivo e essencial para um profissional de saúde. No estágio, o estudante tem muitas oportunidades de trocar informações com colegas, profissionais e usuários da USF, orientados a manter a confidencialidade dos atos que ocorrem nesta interação. Outro aspecto importante que o discente tem oportunidade de desenvolver é a liderança. No trabalho em equipe, as oportunidades são dadas e se torna fundamental para o processo de ensino aprendizagem do estagiário, a capacidade de se empenhar na condução dos processos, liderando ações pertinentes ao estágio. Outras competências não menos importantes, mas essenciais, são as competências colaborativas que se dão, tanto na comunicação interprofissional, como também na liderança colaborativa.

Com carga horária de 60 horas, a disciplina funciona com o acompanhamento de quatro professores e a turma é dividida em grupos de duplas ou trios de alunos que se responsabilizam pela elaboração de um plano de estágio e posterior realização de atividades de promoção e prevenção de saúde em uma USF no município. A turma em questão era composta por 24 alunos e cada 
professor tutor era responsável por duas unidades de estágio. As vivências relatadas neste artigo foram realizadas por um trio de estudantes numa USF que dispunha de uma equipe multiprofissional mínima e uma equipe de saúde bucal modalidade I.

A preceptora envolvida neste relato de experiência teve um papel fundamental nesta construção, junto com a comunidade e equipe de saúde, para realização das ações do estágio. Esta buscou estreitar relações interpessoais e a distância entre o saber teórico e a prática, além de orientar, dar suporte, ensinar e compartilhar experiências que contribuíram para melhorar a formação desses estudantes, sendo um dos pilares do processo de integração ensino-serviço-comunidade.

Desta forma, no período de cinco meses, entre julho e novembro em 2018, o grupo de acadêmicos, mediante a orientação e participação da preceptora e sua equipe de saúde da família, e da docente; realizaram diversas atividades. Para descrever as duas principais vivências desenvolvidas, os dados deste relato de experiência foram alcançados por meio de observação direta dos estudantes durante as atividades do estágio que ocorreram na USF em questão, utilizando como base de registro, o diário de campo e o portfólio crítico reflexivo (PCR) construído durante os encontros e que foi utilizado como ferramenta de avaliação do componente curricular. Dessa forma, aqui serão apresentadas as vivências do "Grafite que traz vida" e a construção da Horta Comunitária.

\section{A vivência "Grafite que traz vida"}

Nas primeiras semanas do estágio, os estudantes juntamente com a preceptora, a professora tutora e as Agentes Comunitárias de Saúde (ACS), dedicaram-se a conhecer a população da área de abrangência desta USF. Foram realizadas visitas domiciliares, momentos de diálogo com as ACS sobre o perfil dos usuários da USF, reconhecimento do território e equipamentos sociais, bem como a análise do prontuário eletrônico da USF.

De acordo com os dados cadastrados no prontuário eletrônico, a população adscrita à USF Argemiro de Figueiredo era de 3135 pessoas, sendo em sua maioria mulheres $(56,9 \%)$, nas faixas etárias de 30 a 34 anos $(4,3 \%)$ e de 55 a 59 anos $(4,3 \%)$. Um grande número de usuários apresentava doenças crônicas, como hipertensão arterial $(n=622)$ e diabetes $(n=223)$. Além disso, foi possível perceber também que um número considerável de usuários apresentava problemas de saúde mental $(n=268)$. Cabe destacar que o bairro teve seu projeto elaborado pela prefeitura municipal, com a centralização de diversos equipamentos sociais fundamentais para assistir à população ali disposta, tais como: Clube de Mães, Lavanderia Municipal, Creche, Escola de Ensino Fundamental e a própria USF. Mesmo com essa estrutura, problemas sociais são presentes na comunidade, como desemprego, criminalidade, pobreza e violência; decorrentes, principalmente, do processo de gentrificação e da desigualdade social presentes na área.

Desse modo, tendo em vista alto número de usuários que sofriam de problemas relacionados à saúde mental, bem como a dificuldade relatada pela equipe de saúde da USF em trabalhar com esse público, percebeu-se a necessidade de desenvolver ações de promoção de saúde com usuários com esse perfil, almejando não apenas explicar as causas, consequências e resoluções destes transtornos, mas também fortalecer o vínculo entre a comunidade e profissionais da saúde a partir de atividades que demonstrassem a importância do acolhimento e da integralidade no atendimento na ESF, bem como destacar a relevância da criação de espaços promotores de saúde na $\mathrm{AB}$.

Sendo assim, tendo em vista grande resistência dos usuários com problemas de saúde mental em participar de atividades na unidade, os discentes e demais profissionais envolvidos perceberam a necessidade de inovar a forma de 
abordagem da comunidade e executar uma ação em saúde que valorizasse seu estilo e cultura. A partir daí, notou-se a importância de enaltecer a arte urbana presente naquele território.

Desse modo, a vivência proposta intitulada de "Grafite que traz vida" foi realizada durante o mês de setembro, em virtude de ser o período do ano dedicado à conscientização da população sobre a importância da prevenção ao suicídio por meio da campanha nacional conhecida como Setembro Amarelo. É válido ressaltar que a escolha do grafite como arte se deu buscando não apenas valorizar o estilo cultural daquele território, mas também estimular a participação dos usuários com problemas de saúde mental, propiciando, assim, que a comunidade deixasse de enxergar a unidade de saúde como um espaço distante de sua realidade e destinado apenas para cuidar de doenças, e passasse a vê-la como um espaço que também se enquadra à identidade local, fortalecendo, assim, o sentimento de pertencimento àquele lugar.

Com isso, a ação consistiu de três momentos: no primeiro, os acadêmicos realizaram uma dinâmica que tinha a finalidade de proporcionar um momento de reflexão sobre a importância da vida. No segundo, os participantes se expressaram por meio de desenhos. em resposta à seguinte pergunta: o que é vida para você? Por fim, no terceiro momento, foi feito o grafite no interior do muro da USF embasado nos desenhos resultantes do momento anterior. Nessa etapa da ação, os participantes tiveram auxílio de um grafiteiro que deu instruções da técnica a ser empregada.

É válido destacar que participaram desta vivência não só o público de saúde mental, mas também os demais usuários que estavam presentes na USF, bem como toda a equipe da unidade. Os acadêmicos, juntamente com a professora tutora e preceptora, conduziram tais momentos.

A dinâmica inicial foi fundamentada na importância de conhecer a si e o outro. Enquanto todos estavam de olhos vendados e em círculo, os interlocutores da dinâmica citavam características de um participante aleatório e pediam para outro dizer de quem se tratava. A proposta deste primeiro momento era levar a mensagem sobre a importância de serem sensíveis e compreensivos com àqueles que os cercam, destacando, assim, a finalidade da campanha Setembro Amarelo.

Dando continuidade, os participantes responderam por meio de desenhos à seguinte pergunta: o que é vida para você? Para a realização deste momento, os estudantes organizaram previamente todo o material necessário para a realização do desenho e pintura, sendo disponibilizado, então, folhas de papel e lápis de cor para os participantes. Foram obtidos diversos resultados neste segundo momento, tais como: desenhos relacionados à família, à natureza, ao trabalho, aos costumes daquela população. Em alguns foram escritas mensagens e trechos de músicas que faziam alusão à vida.

O terceiro momento da vivência consistiu na realização do grafite propriamente dito. Apesar da presença do profissional desta arte, os desenhos feitos no momento anterior foram repassados para as paredes da USF pelos próprios participantes, após a instrução pelo grafiteiro. Foi, de fato, um momento muito descontraído e de extrema importância no que diz respeito à impressão da identidade local e individual e ao reforço do sentimento de pertencimento de cada um àquele lugar, desde os usuários aos profissionais de saúde.

É válido destacar que a proposta de realizar o grafite nos muros da unidade se deu por causa da necessidade de revitalização daquele ambiente. Essa construção contou com a interação da comunidade e equipe da USF desde a preparação do muro para receber a arte, seja por meio da doação do material necessário para o preparo das paredes ou até mesmo na colaboração com a mão de obra.

Desta forma, percebe-se que esta vivência alcançou resultados muito além dos esperados no 
que diz respeito aos objetivos do trabalho com grupos de saúde mental durante o período do Setembro Amarelo. Pode-se afirmar que tal vivência fortaleceu $o$ vínculo entre toda a comunidade e equipe da USF em questão.

\section{A construção da Horta Comunitária}

Esta atividade, por sua vez, foi desenvolvida gradativamente durante o estágio, compreendendo vários momentos, tais como realização de campanhas a fim de arrecadar sementes, mudas de plantas e materiais necessários para a preparação da horta e do local para o plantio.

O local destinado à horta comunitária encontrava-se em situação imprópria para o cultivo de quaisquer plantas, com formigueiros, acúmulo de lixo e sem terra suficiente e adequada para o plantio. É válido ressaltar que o envolvimento da comunidade para a criação deste espaço se deu desde esta etapa. Os usuários participaram de diversas maneiras, seja realizando a correção do solo, ou preparando o mesmo com o adubo orgânico adquirido por meio de doações e/ou oferecidos pelos acadêmicos e pela própria equipe da USF.

Os pneus e paletes utilizados na horta foram obtidos pela própria comunidade a partir das campanhas realizadas para arrecadar tais materiais. Além disso, foi realizado um brechó de roupas, sapatos e acessórios com doações e todo o dinheiro da venda foi revertido para revitalização do espaço. A preparação e pintura do material também foi feita em conjunto, com a interação mútua entre usuários, equipe da unidade e acadêmicos.

A importância da revitalização deste ambiente não consistiu apenas na necessidade de melhorar a estética do lugar, mas também em oferecer melhor conforto e bem-estar aos usuários e à própria equipe, uma vez que com o preparo do solo houve a remoção de uma grande quantidade de plantas que são consideradas sem valor e que apenas atraem vário tipos de insetos que podem vir a prejudicar a saúde das pessoas que frequentam a USF.

Após a preparação do ambiente para receber as plantas, foi realizado o momento do plantio, com uma interação intersetorial articulada entre a equipe de saúde da USF, comunidade e alunos da Creche Municipal Lourdes Loureiro, localizada ao lado da USF na área adstrita à Unidade. Dessa forma, tal ação teve como finalidade enfatizar a importância da criação de elos entre os setores de saúde e os demais equipamentos sociais, fortalecendo, assim, o surgimento de espaços promotores de saúde e permitindo que a comunidade passasse a compreender o espaço da USF para além da doença, destacando, assim, caráter inovador desta vivência.

Nesse sentido, as crianças foram junto com as professoras para a área da USF e, primeiramente, foi realizada uma conversa inicial em que se procurou fazer uma associação entre o cultivo das plantas e o cultivo da vida, relacionando tais cultivos com a importância do cuidado e preservação do meio ambiente.

O momento do plantio propriamente dito ocorreu logo em seguida. As crianças vieram da creche vizinha à USF, foram divididas em grupos e cada grupo foi monitorado por um acadêmico, professora tutora ou preceptora. Durante o plantio foi ressaltada, para cada grupo de crianças, a importância das plantas, como também foi ensinado como plantar e cuidar da planta cultivada. Todas as crianças tiveram a oportunidade de entrar em contato com a terra e com as mudas, bem como realizar o plantio. É válido destacar que os usuários que se encontravam na unidade, bem como a equipe da USF também foi convidada para participar deste momento. A maioria destes mostrou interesse e, assim, envolveram-se nesta vivência.

Ao término do plantio houve a distribuição de sementes para cada criança. $\mathrm{O}$ intuito desta distribuição foi fazer com que elas conseguissem 
praticar a questão do cuidado que foi ensinado e passar para os seus familiares o que foi aprendido. Além disso, outro propósito desta distribuição foi promover a construção da interação entre o espaço da USF com as famílias das crianças, fortalecendo, assim, o vínculo entre os dois ambientes.

\section{DISCUSSÃO}

O estágio na ESF se configura como uma conexão entre a teoria e a prática, no qual se constrói a identidade profissional por ser um espaço rico de aprendizado $^{14}$. Sendo assim, as vivências relatadas permitiram que os estudantes desenvolvessem atitudes de cidadania, empatia, que ao mesmo tempo abrangem dimensões formativas no aspecto não só cognitivo, mas também afetivo, quando se envolvem com a comunidade, na escuta qualificada e atenção às fragilidades percebidas durante as vivências ${ }^{15}$.

O contato efetivo do estudante com a comunidade torna possível o estreitamento das relações interpessoais, aguçando a percepção do indivíduo que, inserido no meio social, tem uma formação mais humanizada na saúde ${ }^{16}$. Por este motivo, é fundamental reconhecer o que o estudante traz enquanto conhecimento teórico e sentimentos, além de ser de grande relevância o reconhecimento do trabalho coletivo entre o preceptor e o estudante ${ }^{17}$. É válido destacar que a diversidade de experiências vividas no território oportunizam um processo educativo críticoreflexivo, com conhecimento do território da ESF, das interações socioculturais, que perpassam a formação em saúde e a consequente produção do cuidado em saúde bucal ${ }^{18}$.

A atuação dos discentes durante os estágios de promoção de saúde trouxe contribuições no processo de fortalecimento do vínculo entre os profissionais de saúde e os usuários. Sabe-se que no campo da saúde pública, o vínculo representa uma conexão entre os conceitos de humanização, responsabilização, acolhimento e integralidade ${ }^{19}$.
Uma das diretrizes da ESF é possibilitar a criação do vínculo profissional-usuário por meio do trabalho do ACS, o qual realiza a intermediação entre as famílias e a equipe de saúde ${ }^{20}$.

Indubitavelmente, a participação dos futuros profissionais durante esse processo tem como consequência positiva a formação de cirurgiõesdentistas sensíveis e aptos a reconhecerem a importância desse elo no desempenho de suas atividades na unidade de saúde. Sendo assim, percebe-se a importância da consolidação de laços entre os atores envolvidos nessas ações, por meio dessa conexão onde os profissionais conseguem obter o conhecimento das subjetividades, individualidades, e condições de vida das famílias, e, a partir disso, tornam-se capazes de estimularem interações próximas e solidárias, fazendo com que os cuidados pontuais e mecanicistas sejam substituídos por cuidados criativos e transformadores ${ }^{21}$.

Ademais, é válido destacar que o vínculo e o acolhimento existentes no âmbito da saúde pública representam um importante marco deste campo, uma vez que se trata da inversão do modelo técnico-assistencial outrora operado $^{22}$. Como exemplo disso, cabe citar a experiência relatada por Carvalho et al. $(2020)^{23}$, na qual se ressalta que, por meio da construção de um espaço promotor de saúde numa determinada UBS, houve uma melhoria da estratégia de acolhimento e isso resultou numa maior aproximação da comunidade com a equipe de saúde, havendo, assim, o fortalecimento do vínculo entre esses dois atores. Sendo assim, tendo em vista o que foi posto, é de grande relevância que, além dos ACS, os demais profissionais integrantes da equipe de ESF busquem, por meio de seus trabalhos, fortalecer o elo que deve existir entre o usuário e os profissionais.

As atividades desenvolvidas pelos estudantes de Odontologia no decorrer do estágio na ESF apresentaram significantes resultados tanto 
para os trabalhadores e comunidade quanto para sua própria formação. Isso mostra que a construção de espaços de promoção da saúde são efetivos para o envolvimento do indivíduo com o seu autocuidado e a sua reabilitação. Além disso, esses espaços se constituem como estratégia pedagógica, favorecendo a concepção ampliada de saúde numa perspectiva de ressignificação das práticas de produção do cuidado, considerando nesse contexto o fortalecimento da autonomia e o protagonismo dos discentes ${ }^{24}$.

É correto afirmar que o território da ESF oportuniza experiências de ensino-aprendizagem extramuros, propiciando aos estudantes enxergar a APS como espaço para criação e invenção no desenvolvimento de práticas educativas de promoção da saúde e de uma clínica ampliada, que aproximam o serviço de saúde, a comunidade e a formação acadêmica ${ }^{25}$. A pesquisa realizada por Santos et al. $(2013)^{26}$ com acadêmicos de Odontologia, confirma o que foi posto, uma vez que, todos os estudantes que participaram do estudo afirmaram que as experiências de estágios extramuros na ESF influenciaram de maneira positiva a sua formação acadêmica, uma vez que a tornou mais humanista, integral, crítica e reflexiva, como preconizam as DCN do curso. Sendo assim, cabe destacar que, nas vivências descritas neste artigo, a ESF de fato possibilitou a construção de práticas educativas que permitiram a aproximação de escolares, usuários de saúde mental, equipe de Saúde da Família, docentes e discentes na construção de uma $\mathrm{AB}$ promotora de saúde e com uma ambiência acolhedora, contribuindo grandemente no processo de formação dos acadêmicos envolvidos.

Nesse sentido, a promoção da saúde se insere na perspectiva de um novo modelo de atenção a saúde que objetiva buscar qualidade de vida para a população não só por meio da análise do âmbito biológico, mas sim tomando como base os determinantes das esferas socioeconômica, política, cultural e emocional responsáveis por moldar os indivíduos ${ }^{27}$.

Apesar da promoção da saúde na ESF presumir uma interação intersetorial por meio da articulação dos serviços de saúde com outros equipamentos sociais ${ }^{28}$, nota-se que uma de suas limitações é o desafio em articular diferentes setores e formar espaços promotores de saúde nas comunidades, dificultando, assim, o contato constante dos indivíduos com os instrumentos de apoio e bem-estar ${ }^{29}$.

A oficina do grafite, realizada com usuários de saúde mental, permitiu o trabalho consciente para desenvolver a relação de públicos com a arte. Trata-se de uma ferramenta importante para o desenvolvimento da percepção, imaginação e capacidade crítica, e assim permite que as pessoas analisem a realidade e desenvolvam a criatividade de maneira a mudá-la ${ }^{30}$. A abordagem artística é uma porta para a humanização, sendo um recurso potente que pode ser usado tanto por educadores, como por profissionais de saúde e não só para a promoção da saúde de seus usuários. Mas também, para a melhoria de sua própria qualidade de vida, posto que os profissionais de saúde, em sua maioria, também é educadora, exercendo este papel dentro da própria equipe, com o usuário e seus familiares assim como com toda a comunidade em que se insere ${ }^{31}$. A vivência relatada por LeónCedeño et al. (2017) ${ }^{32}$, além de destacar a importância da intersecção entre universidade, comunidade e equipe de saúde, também enfatizou a importância do encontro entre a abordagem artística e as questões comunitárias e sociais, destacando, assim, a relevância da criação de espaços que viabilizem a potência do sujeito quando em convivência com o outro.

A horta comunitária construída na USF apresentou como um espaço potencial de socialização e aumento de interações sociais a partir de atividades desenvolvidas no seu cuidado junto com a comunidade. Tal fato, ressalta a sua 
importância na apropriação da unidade de saúde enquanto um espaço coletivo, de criação de rede de suporte afetivo, diminuição de isolamento social e apropriação de demais espaços e serviços do território $^{33}$. Outro exemplo de interação ensinoserviço-comunidade descrita na literatura por Carvalho et al. $(2020)^{23}$, relatando a experiência que também traz como um dos destaques a construção de uma horta comunitária. Cabe aqui destacar que os autores citaram que mesmo os usuários que desconheciam da existência de tal espaço, passavam a admirar e visitar o local, tornando, assim, perceptível o fortalecimento do vínculo entre a unidade de saúde e população a partir de espaços como estes ${ }^{23}$.

Ademais, esse espaço de socialização proporcionado pela horta permite a limpeza de algumas áreas e uma melhoria considerável no ambiente e o compartilhamento de experiências e resgate da cultura popular no cuidado das pessoas, sendo uma oportunidade de retomar sociabilidades perdidas no meio urbano ${ }^{34}$.

\section{CONSIDERAÇÕES FINAIS}

Esse processo de integração ensino-serviço permitiu o destaque da importância dos estágios para a criação de espaços que possibilitam a elaboração de dinâmicas educativas que tenham como objetivo permitir o reconhecimento do SUS como sistema de relevância social. Sendo assim, vivências como essas são capazes de trazer benefícios para a sociedade, como também fortalecem a formação acadêmica e pessoal dos estudantes envolvidos, oferecendo, assim, resultados positivos para a universidade.

Limitações para realização das atividades também foram observadas, sendo um destaque a falta de interprofissionalidade. Apesar de ter havido a participação dos ACS, da cirurgiã-dentista e do técnico em saúde bucal que atuavam na equipe, percebeu-se a dificuldade do envolvimento e da colaboração dos profissionais da enfermagem e da medicina. Isso aconteceu devido às altas demandas relacionadas ao atendimento clínico da população que impossibilitaram a participação, de forma integrada, de todos os profissionais da ESF durante as atividades realizadas.

No entanto, tais experiências também trouxeram perspectivas futuras, como o fortalecimento da fitoterapia e do uso de plantas medicinais pela comunidade, a utilização do espaço revitalizado para realização de atividades de promoção da saúde, além da melhoria na ambiência da USF que permite maior acolhimento aos usuários. Outra perspectiva diz respeito à oportunidade da sustentabilidade das ações desenvolvidas em colaboração com os trabalhadores, comunidade e a universidade; a participação desta última tem sido realizada por meio adesão de novos grupos de estagiários à USF. Esta adesão tem permitido a perpetuação destes trabalhos desenvolvidos, bem como o desenvolvimento de novos projetos que visam promover saúde por meio da interação universidade, comunidade e equipe de saúde; fortalecendo assim, cada vez mais, o vínculo entre estes atores.

Além disso, notou-se a grande relevância do papel do estudante durante estágios na ESF, pois os mesmos trazem inovações e motivações para o trabalho em saúde. Nas vivências que foram descritas neste artigo cabe destacar como inovação agregada pelos estudantes a própria ideia do fortalecimento do vínculo entre a comunidade e equipe de saúde por meio do desenvolvimento das atividades relatadas. A vivência "Grafite que traz vida" foi capaz de despertar a atenção e o interesse da comunidade, bem como a criação do sentimento de pertencimento àquele lugar. As dinâmicas, a vivência do plantio com as crianças da creche, a preocupação e o olhar para a melhoria da ambiência da USF, também foram ideias trazidas pelos estudantes que merecem destaque. Sendo assim, quando as experiências profissionais dos 
preceptores no trabalho em comunidade são associadas às contribuições dos estudantes e ao conhecimento teórico-prático dos professores tutores, têm-se, como resultado, a qualificação do cuidado em saúde.

\section{ABSTRACT \\ Health-promoting spaces in Primary Health Care: the experience of undergraduate dentistry students at the State University of Paraíba}

The study aims to report the experience of a group of dentistry students from the State University of Paraíba, which took place in the second semester of 2018, during the process of forming a health-promoting space that provided the meeting of culture and art with the System Health Unit at the Family Health Unit (FHU) Argemiro de Figueiredo, located in the municipality of Campina Grande. The construction of this space took place during the Internship in the Family Health Strategy I, a curricular component offered in the fourth semester of the course. Such an environment was created from the experience entitled "Graffiti that brings life", as well as through the construction process of the Community Garden in that FHU. The aforementioned activities were marked by the strong interaction between academics, the community, the health team, and social equipment present in the area assigned to the FHU, allowing the strengthening of the bond between the health team and the population. In this process of living in the community, it was observed the importance of the presence of dentistry students in the Primary Care (PC) scenario. Such presence enabled them to recognize the relevance of comprehensive care, understanding that the role of the dental surgeon in PC goes far beyond guaranteeing oral health care for the population. Also, the construction of a health-promoting space allowed the strengthening of ties between users and workers, enabling the community to understand the BHU space in addition to the disease.

Descriptors: Family Health Strategy. Training Support. Dentistry. Health Promotion.

\section{REFERÊNCIAS}

1. Brasil. Ministério da Saúde. Secretaria de Atenção à Saúde. Departamento de Atenção Básica. Política Nacional de Atenção Básica - Brasília: Ministério da Saúde, 2006.

2. Brasil. Ministério da Saúde. Secretaria de Atenção à Saúde. Departamento de Atenção Básica. Caderno de Atenção Primária/ Rastreamento. 1 ed., 1 reimpr. V 2. Brasília, 2013.

3. Oliveira MAC, Pereira IC. Atributos essenciais da Atenção Primária e a Estratégia Saúde da Família. Revista Brasileira de Enfermagem. 2013;66:158-64.

4. Agostinho MR, Oliveira MC, Pinto MEB, Balardin GU, Harzhein E. Autopercepção da saúde entre usuários da Atenção Primária em Porto Alegre, RS. R Bras Med Fam Comum. 2010;5(17):9-15.

5. Brasil. Ministério da Saúde. Portaria $\mathrm{n}^{\circ}$ 2.436, de 21 de setembro de 2017. Aprova a Política Nacional de Atenção Básica, estabelecendo a revisão de diretrizes para a organização da Atenção Básica no âmbito do Sistema Único de Saúde (SUS). Brasília, DF: Ministério da Saúde, 2017. [Acesso em: 28 jul. 2020]. Disponível em: https://bvsms.saude.gov.br/bvs/saudelegis/g m/2017/prt2436_22_09_2017.html.

6. Santos RCA, Miranda FAN. Importância do vínculo entre profissional-usuário na Estratégia Saúde da Família. Cienc Cuid Saude. 2014;13(3):556-62.

7. Brasil. Constituição da República Federativa do Brasil: promulgada em 5 de outubro de 1988. [Acesso em: 03 ago. 2020]. Disponível em: http://www.planalto.gov. br/ccivil_03/constituicao/constituicaocompi lado.htm.

8. Hora DL, Erthal RMC, Souza CTV, Hora EL. Propostas inovadoras na formação do profissional para o Sistema Único de Saúde. 
Trab Educ Saúde. 2013, 11(3):471-86.

9. Brasil. Ministério da Saúde e Ministério da Educação. Pró-saúde: Programa Nacional de Reorientação da Formação Profissional em Saúde. Brasília, 2007.

10. Brasil. Ministério da Saúde e Ministério da Educação. Aderência dos cursos de graduação em Enfermagem, Medicina e Odontologia às Diretrizes Curriculares Nacionais. Brasília, 2006.

11. IBGE - Instituto Brasileiro de Geografia e Estatística. Cidades e Estados: Campina Grande - PB. [Acesso em: 31 jul. 2020]. Disponível em: https://www.ibge.gov.br /cidades-e-estados/pb/campina-grande.html.

12. DATASUS - Departamento de Informática do SUS. Índice de Gini e da renda domiciliar per capita - Paraíba. [Acesso em: 31 jul. 2020]. Disponível em: http://tabnet.data sus.gov.br/cgi/ibge/censo/cnv/ginipb.def.

13. DATASUS - Departamento de Informática do SUS. Equipes de Saúde - Paraíba. [Acesso em: 31 ago. 2020]. Disponível em: http://tabnet.datasus.gov.br/cgi/tabcgi.exe?c nes/cnv/equipepb.def.

14. Bulgarelli AF, Souza KR, Baumgarten A, Souza JM, Rosing CK, Toassi RFC. Formação em saúde com vivência no Sistema Único de Saúde (SUS): percepções de estudantes do curso de odontologia da Universidade Federal do Rio Grande do Sul (UFRGS), Brasil. Interface (Botucatu). 2014; 18(49):351-62.

15. Brasil. Resolução CNE/CES nº. 3, de 19 de fevereiro de 2002. Institui as Diretrizes Curriculares Nacionais do Curso de Graduação em Odontologia. Brasília, 2002. [Acesso em: 02 ago. 2020]. Disponível em: http://portal.mec.gov.br/cne/arquivos/pdf/C ES032002.pdf.

16. Pereira RVS, Dantas LS, Bernardino IM, Silva VC, Madruga RCR, Lucas RSCC.
Preceptoria nos serviços públicos especializados como cenário de aprendizagem na formação em Odontologia. Rev ABENO. 2018; 18(4):176-85.

17. Forte FDS, Pessoa TRRF, Freitas CHSM, Pereira CAL, Carvalho Junior PM. Reorientação na formação de cirurgiõesdentistas: o olhar dos preceptores sobre estágios supervisionados no Sistema Único de Saúde (SUS). Interface: Comunic Saúde Educ. 2015;19 (1):831-43.

18. Arouca R, Rego STA, Machado M. Das políticas de formação às salas de aula: reflexões sobre a questão curricular em odontologia. Rev Bras Odontol. 2007; 64(34):274-8.

19. Santos RCA, Miranda FAN. A importância do vínculo entre profissional-usuário na Estratégia Saúde da Família. Rev Enferm UFSM. 2016;6(3):350-9.

20. Ilha S, Dias MV, Backes DS, Backes MTS. Vínculo profissional-usuário em uma Equipe da Estratégia Saúde da Família. Cienc Cuid Saude. 2014;13(3):556-62.

21. Braga GMAM, Mafra SCT, Silva EP, Gomes AP, Melo MSS. Percepção do trabalho do Agente Comunitário de Saúde pelos usuários atendidos nas Unidades Básicas de Saúde da Família de Viçosa, MG: Tarefas realizadas e normas prescritas. Oikos: Rev Bras Econ Domést. 2016;27(1):79-95.

22. Backes DS, Pereira AD, Marchiori MT, Rupolo I, Backes MTS, Büscher A. Vínculo profissional-usuário: competência para a atuação da Estratégia Saúde da Família. Av Enferm. 2015;33(2):222-9.

23. Carvalho ALB, Braga LRA, Silva DF, Araujo JBF, Amorim MC, Magalhaes MJO. Vivências de acolhimento na unidade de saúde da família: a experiência do cantinho do chá na UBS do Grotão, João Pessoa - PB. 
Saúde em Redes. 2020; 6(1):205-17.

24. Almeida JRS, Lima MCF, Castro C, Praxedes CES, Amaral MES, Sousa RMRB. Espaço de promoção da saúde na graduação em Odontologia: (re)significando saberes e práticas na produção do cuidado. Rev. ABENO. 2019;19(2): 127-34.

25. Forte FDS; Pontes AA, Morais HGF, Barbosa AS, Nétto OBS. Olhar discente e a formação em Odontologia: interseções possíveis com a Estratégia Saúde da Família. Interface: Comunic Saúde Educ. 2019;23: e170407.

26. Santos KT, Ferreira L, Batista RJ, Bitencourt CTF, Araújo RP, Carvalho RB. Percepção discente sobre a influência de estágio extramuro na formação acadêmica odontológica. Rev Odontol UNESP. 2013; 42(6): 420-5.

27. Silva MAM, Pinheiro AKB, Souza AMA. Promoção da saúde em ambientes hospitalares. Rev Bras Enferm. 2011;64(3):596-9.

28. Mori AY, Ogata MN. Cuidado Intersetorial: Promovendo a articulação entre a Equipe de Saúde da Família e uma Creche. Rev APS. 2010;13(4):518-22.

29. Lemos MP, Cavalcante Júnior FS. Psicologia de orientação positiva: uma proposta de intervenção no trabalho com grupos em saúde mental. Ciênc Saúde Colet. 2009;14(1):233-42.
30. Barbosa AM. Arte/educação no Brasil. Coleção Debates. 7. ed. São Paulo: Perspectiva; 2012.

31. Coscrato G, Bueno SMV. A luz da arte nos centros de atenção psicossocial: interface com o cuidado. Cad Bras Saude Mental. 2009;(2):142-9

32. León-Cedeño AA, Ortolan MLM, Sei MB. A convivência como promotora de saúde mental: aproximações entre a Associação Ciranda da Cultura e os serviços de Centros de Convivência. Saúde Transform Soc. 2017; 8(1):129-137.

33. Santos EAD. Grupo de Horta e Plantas Medicinais: Espaço de Produção de Saúde na Atenção Primária em Unidade Básica de Saúde Pertencente à Rede de Serviços da SMS/São Paulo, CRS Oeste. In: Congresso de Secretários de Saúde do Estado de São Paulo, São Paulo, p. 665-66, 2016.

34. Monteiro D, Mendonça MM. Quintais na Cidade: a experiência de moradores da periferia da cidade do Rio de Janeiro. Agriculturas. 2004;1(0):29-31.

\section{Correspondência para:}

Gabriella Barreto Soares

e-mail: gabriella.barreto@yahoo.com.br Av Cabo Branco, 2834/401, Cabo Branco 58045-010 João Pessoa/PB 